\title{
PRECISIONES SOBRE EL VALOR SEMÁNTICO \\ DEL VERBO BAПTIZ $\Omega$ EN EL NUEVO TESTAMENTO, A LA LUZ DE SUS RELACIONES CON SINTAGMAS PREPOSICIONALES
}

\author{
C. Rita Jorge Hernández \\ IES Mencey Bencomo \\ carmenritajorgeh@gmail.com
}

\begin{abstract}
A Juan Barreto, que me enseñó a leer de otra forma el NT
\end{abstract}

\begin{abstract}
RESUMEN
Partiendo del análisis de los casos de uso del verbo $\beta \alpha \pi \tau i ́ \zeta \omega$ con sintagmas preposicionales en el corpus del Nuevo Testamento, se pretende precisar la evolución del valor semántico de dicho verbo, indagar en las relaciones entre Sintaxis y Semántica, y contribuir a la exégesis de los textos analizados.

Palabras Clave: Nuevo Testamento, Semántica, Sintaxis, bautizar, preposiciones.

\author{
PRECISIONS ABOUT THE SEMANTIC VALUE OF THE VERB BAПTIZ $\Omega$ \\ IN THE NEW TESTAMENT IN THE LIGHT OF ITS RELATIONS \\ WITH PREPOSITIONAL SYNTAGMS
}

\section{ABSTRACT}

Starting from the analysis of the cases of use of the verb $\beta \alpha \pi \tau i \zeta \omega$ with prepositionals syntagms in the corpus of the New Testament, we intend to specify the evolution of the semantic value of this verb, to investigate the relationships between Syntax and Semantics, and to contribute to the exegesis of the sense of analyzed texts.

KeY WORDS: New Testament, Semantics, Syntax, baptize, prepositions.

\section{PRESUPUESTOS}

En el estudio que sigue, a propósito de los usos de sintagmas preposicionales en dependencia sintáctica de formas del paradigma del verbo $\beta \alpha \pi \tau i \zeta \omega$ (una de las «caras» del lexema * $\beta \alpha \pi \tau \imath \sigma-;$ otras posibles serían los sustantivos $\beta \alpha ́ \pi \tau \imath \sigma \mu \alpha$,

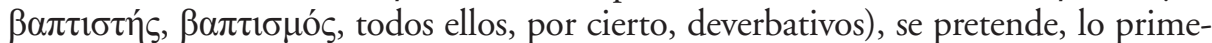
ro, indagar en las relaciones más hondas (y, por tanto, en las fronteras) entre lo semántico y lo sintáctico; definir con exactitud el valor semántico de las preposiciones 
empleadas con dicho verbo; y, por último, precisar, contextualizándolo, el significado del lexema verbal en los pasajes objeto de análisis, todos los del corpus del Nuevo Testamento en los que el verbo rige un sintagma con preposición.

Se parte, como fundamento teórico, del método de análisis del profesor Juan Mateos ${ }^{1}$, que define el valor semántico de una palabra descomponiendo su significado en semas denotados ${ }^{2}$ (los que conforman su valor esencial, sustancial, nuclear) y connotados (adscritos a los anteriores, susceptibles de adquirir un mayor o menor «realce» en una producción lingüística dada, pero implícitos, previstos, en el lexema). Se analizan así las relaciones que el lexema establece con otras palabras mediante preposición, comprobando hasta qué punto puede variar su connotación por influencia de las relaciones sintácticas que establezca, en la frase, con otros lexemas. Finalmente se precisa cómo se concreta, en cada caso, lo denotado y lo connotado, y las repercusiones que, en el valor semántico de la palabra, puedan producirse a partir de las relaciones sintácticas que establezca.

Teniendo en cuenta que las preposiciones funcionan como índices de relación sintáctica entre palabras, dotados, según la terminología del profesor Mateos, de un valor semántico de relación (de lugar, tiempo, modo, instrumento, causa... $)^{3}$, en el uso de una u otra, en la elección de una construcción sintáctica u otra, así como en el valor semántico de la palabra regida por la preposición, podremos apreciar, por un lado, los valores connotados del lexema regente (en este caso el verbo $\beta \alpha \pi \tau i \zeta \omega$ ) que se realizan en tal contexto y, por otro, las posibles repercusiones en su valor denotado que tal uso pueda implicar.

Se trata, por tanto, de aplicar el método de análisis semántico del profesor Mateos no ya a palabras aisladas 4 , para definir los distintos semas que conforman su significado, sino a las relaciones que una palabra puede establecer en un conjunto de producciones y definir, en cada caso, qué semas (denotados o connotados) de la palabra han cobrado mayor "presencia», mayor «relevancia» en la construcción con tal o cual sintagma preposicional.

De acuerdo con las pautas metodológicas aceptadas por el grupo de investigación G.A.S.C.O.5 (que desarrolla el método del profesor Mateos), los semas que constituyen el significado denotado del lexema en cuestión serían:

${ }^{1}$ Mateos, J. (1989): Método de análisis semántico aplicado al griego del Nuevo Testamento, Ed. El Almendro, Córdoba.

${ }^{2}$ Véase, para una definición de los conceptos de denotación y connotación, Peláez, J. (1996): Metodología del Diccionario Griego-Español del Nuevo Testamento, Ed. El Almendro, Córdoba, pp.73 y 74 .

${ }^{3}$ Ibidem se define la especie semántica Relación como «conexiones que existen, que se descubren, o conexiones que crea y formula la mente entre entidades y/o hechos» (pág. 69).

${ }^{4}$ Eso lo hace ya con precisión sistemática el Diccionario Griego-Español del Nuevo Testamento (DGENT), cuyos primeros cinco fascículos han sido ya publicados en Ed. El Almendro, Córdoba 2000-2012.

${ }^{5}$ Grupo de Análisis Semántico de la Universidad de Córdoba. Entre otras, su tarea más relevante es la elaboración del diccionario citado en la nota anterior. 
$\mathrm{H}+\mathrm{R}+\mathrm{E}$

El lexema del verbo $\beta \alpha \pi \tau i \zeta \omega$ denota un Hecho $(H)$, una acción, que implica una Relación (R), en este caso de lugar, con una Entidad (E), en este caso un medio líquido. Así que $\beta \alpha \pi \tau i \zeta \omega$ significa, en principio (como palabra del habla corriente), «meter en un líquido», "sumergir».

Los valores connotados de este lexema, susceptibles de evidenciarse (o no) en una frase cualquiera, serían los siguientes:

1.- $\mathrm{H}+\mathrm{R}+\mathrm{E} \leftarrow \mathrm{R} 1-\mathrm{E} 1$

Esta primera connotación de la palabra consiste en una Relación (R1), explícita o no, de agentividad, con una Entidad (E1), animada, el agente de la acción que el lexema denota, o sea, quien realiza la acción que el verbo refiere; lo que, en la sintaxis de la frase, vendría a formularse como un sujeto agente en nominativo, o como un complemento agente en forma de sintagma preposicional si el verbo se conjuga en pasiva. Hay que advertir que tal entidad se formularía como genitivo subjetivo en el caso de que el lexema apareciera en la frase con su "cara» nominal o sustantiva $(\beta \alpha ́ \pi \tau 1 \sigma \mu \alpha)$. Así aparece, de hecho, en bastantes pasajes del corpus considerado: Mc 11,30, Mt 3,7 y 21,25, Lc 7,29 y 20,4 y Hch 1,22, 18,25 y 19,3.

2.- $\mathrm{H}+\mathrm{R}+\mathrm{E} \rightarrow \mathrm{R} 2-\mathrm{E} 2$

El segundo valor connotado del lexema consiste en una Relación (R2), explícita o no, de transitividad, con una Entidad (E2), animada o no, el paciente de la acción que el lexema denota, o sea, el que (la que o lo que) recibe la acción que el verbo refiere; lo que se formularía como un objeto directo en acusativo, o un sujeto paciente en nominativo. En el caso de que el lexema apareciera en la frase con su "cara» sustantiva, esta entidad se formularía como genitivo objetivo, tal como en Mc 7,4.

3.- $\mathrm{H}+\mathrm{R}+\mathrm{E} \rightarrow \mathrm{R} 3 \rightarrow(\mathrm{H} 1+\mathrm{A} 1)$

La tercera connotación supone una Relación (R3) de causatividad con otro Hecho $(\mathrm{H} 1)$, en este caso no una acción propiamente dicha, sino la obtención de un estado de limpieza, que implica un cambio cualitativo, un Atributo nuevo (A1) en el E2, animado o no, objeto de la acción del verbo.

\section{4.- $\mathrm{H}+\mathrm{R}+\mathrm{E} \rightarrow \mathrm{R} 3 \rightarrow\left[(\mathrm{H} 1+\mathrm{A} 1)-\mathrm{R} 4 \rightarrow\left(\mathrm{H}^{\prime}{ }^{\prime}+\mathrm{A} 1^{\prime}\right)\right]$}

Esta connotación de la palabra puede, por un uso metafórico de la misma, transformarse, de modo que el lexema ya no signifique «limpiar» en sentido físico, sino «limpiar» en sentido figurado, en sentido simbólico-ritual, aunque para ello es necesario que el E2, el objeto de la acción del verbo, sea una entidad personal.

El desarrollo sémico, en detalle, sería así:

Denotación: H (Acción) + R (Interioridad) + E (Liquidez)

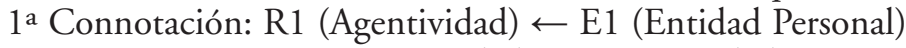

2a Connotación: R2 (Transitividad) $\rightarrow$ E2 (Entidad) 


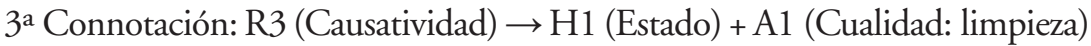
Metaforización: R4 (Simbolización) $\rightarrow$ H1' (Estado ritual) + A1' (Cualidad: limpieza, ritual también)

$\mathrm{B} \alpha \pi \tau i \zeta \omega$ es pues «sumergir en un líquido $(\mathrm{H}+\mathrm{R}+\mathrm{E}),(\mathrm{R} 1)$ alguien (E1), a (R2) alguien o algo (E2), para causarle (R3) un estado de limpieza (H1 + A1), que simboliza (R4) un nuevo estado de limpieza ritual (H1' + A1')».

En el corpus de textos del $N T$, el verbo $\beta \alpha \pi \tau i \zeta \omega$ se usa casi siempre con valor simbólico ${ }^{6}$, o sea, referido a una acción ritual: la entidad objeto que recibe la acción del verbo es personal y la acción sobre ella implica, por tanto, un cambio de estado: de estar sucio, metafóricamente hablando, en sentido figurado, mediante el bautismo, se purificaría, también, evidentemente, en sentido figurado.

Aparte de estas connotaciones, implícitas, intrínsecas, este lexema puede admitir (como cualquier otro) contextualizaciones periféricas, adyacentes, externas, no impuestas por el lexema, expresadas en la sintaxis de la frase mediante complementos circunstanciales de lugar, de finalidad, de causa, o de cualquier otro tipo.

Una vez formulado exhaustivamente el valor semántico del lexema considerado en el corpus de textos del $N T$ («sumergir alguien a alguien en un medio líquido para causar en él un estado de limpieza ritual») cabe preguntarse: ¿con qué preposiciones se pueden construir las formas de este verbo? ¿Dichas preposiciones explicitan en el plano sintáctico relaciones contenidas en la denotación del lexema y en sus connotaciones, o más bien relaciones adyacentes, de las que hemos llamado periféricas o externas a la definición semántica?

\section{ANÁLISIS}

\section{CON LA PREPOSICIÓN Ėv}

A. El sintagma preposicional explicita la relación (R) y la entidad (E) denotadas por el lexema, es decir, el medio líquido en el que se realiza el bautismo: el río Jordán,

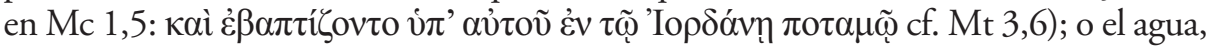

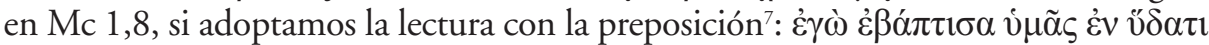
(cf. Mt 3,11, Jn 1,26.31 y 33).

Es pertinente, para nuestro propósito de indagar en las relaciones entre sintaxis y semántica, advertir que, en algunos pasajes del corpus (esta era la otra posible

${ }^{6}$ Excepto en Mc 7,4, pasaje en el que aparece dos veces el lexema, una como verbo y otra como sustantivo, con su denotación propia, sus tres connotaciones, pero sin metaforización.

${ }^{7}$ Se adopta la lectura con preposición debido al valor instrumental de la preposición en hebreo. 
lectura del Mc $\left.1,8^{8}\right)$, el medio líquido denotado (el agua) aparece como dativo

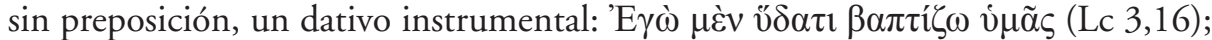

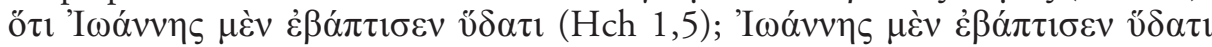
(Hch 11,16). Cabría plantearse si estos cambios en la estrategia sintáctica responderían a un cambio en la denotación del verbo, en el sentido de que, en Lucas y en los Hechos, bautizar no implicara ya "sumergir en líquido" (como se comprue-

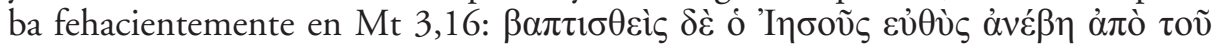
v̋ $\delta \alpha \tau \varsigma)$, sino «mojar con líquido». Bien pudiera ser que el ritual hubiera evolucionado y, en un proceso de abstracción, el agua participara en el ritual como símbolo, no ya como continente del bautizado.

B. La palabra que la preposición relaciona con el verbo, en el mismo nivel de relación que la entidad (E) denotada (de hecho se formula, generalmente, en paralelismo sintáctico con las construcciones analizadas anteriormente), no alude, en rigor, a un medio líquido, sino al espíritu santo en forma de fuego: $\alpha$ vò̀

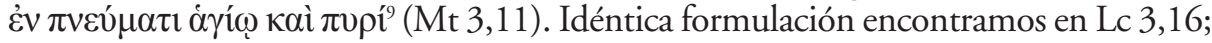
y parecida en Mc 1,8, aunque falte la referencia al fuego, y el pronombre personal, en acusativo, el objeto personal del bautismo, se postponga al verbo: $\alpha$ v̇ंò $\delta \delta \dot{\varepsilon} \beta \alpha \pi \tau i ́ \sigma \varepsilon 1$ $\dot{v} \mu \tilde{\alpha} \varsigma \dot{\varepsilon} v \pi v \varepsilon v ́ \mu \alpha \tau \imath \dot{\alpha} \gamma i \omega^{10}{ }^{10}$. También se alude al espíritu santo en el lugar sintáctico

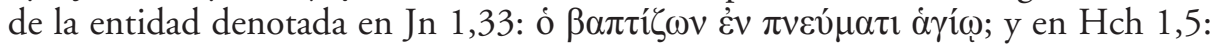

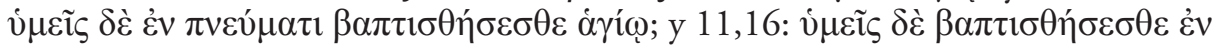

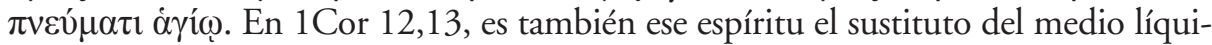
do (aunque se añade, como cualidad que le es propia, el ser uno solo común para todos):

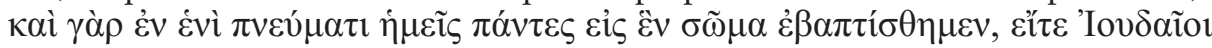

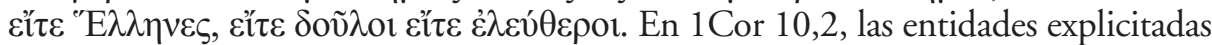

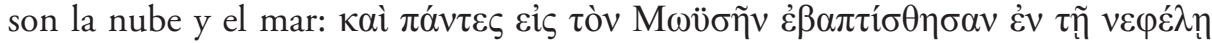

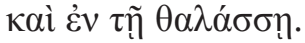

Para explicar usos como estos, ¿̨habría que entender que el valor semántico del lexema verbal se ha metaforizado hasta el punto de que ni siquiera contiene ya en su denotación el medio líquido, o sea, que el «bautizar» que el que va a venir, el Cristo, propone no sólo no necesita del agua (lo cual sería impensable en el rito tradicional), sino que puede realizarse en espíritu (aire, soplo) y hasta en fuego? Más prudente y probable se nos ocurre que lo chocante de la formulación, por recurso a la paradoja (el fuego es la antítesis del agua), sirva para marcar el carácter rompedor, subversivo del bautismo cristiano: la limpieza, la purificación espiritual que el bautismo del Cristo proclama, no se consigue por medio del agua que usaban tradicionalmente los fariseos en sus rituales de purificación y que todavía usa Juan el Bautista antes de la venida del Mesías. Lo que la construcción sintáctica nos indi-

\footnotetext{
${ }^{8}$ Sin preposición en algunos manuscritos.

9 Aunque literalmente dice "en espíritu santo y fuego", se trata de una hendíadis.

${ }^{10}$ Algunos manuscritos presentan el sintagma con preposición y otros sin ella.
} 
ca es que el término «bautizar» ha adquirido, por metaforización, un significado simbólico, específico del argot religioso, que incluso altera su denotación primigenia.

Comentario aparte merecerían los casos de la primera carta a los Corintios de Pablo de Tarso:

En 1Cor 1,2, entendemos que el sintagma preposicional explicita una relación con el medio líquido denotado, que en este caso no es el agua de un río, sino la nube y el mar. La formulación, poética y un tanto grandilocuente, de Pablo, nos dibuja al Dios del Antiguo Testamento bautizando de golpe a su pueblo entero al cruzar el mar Rojo, purificándolo por la acción de las aguas.

Lo más curioso de 1 Cor 12,13 es que no se añade al 'espíritu' el calificativo de 'santo' (acaso ya para entonces el epíteto era demasiado superfluo), sino el cuantificador 'uno', en consonancia con el universalismo que impregna toda la teología

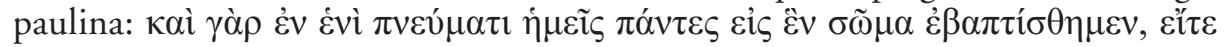

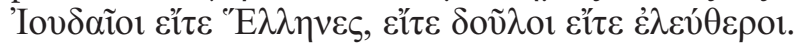

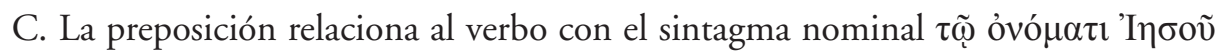

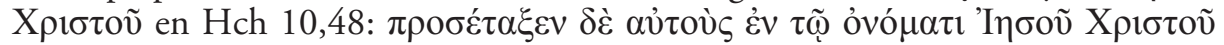
$\beta \alpha \pi \tau \imath \sigma \theta \tilde{\eta} v \alpha \iota$. Tal relación sintáctica explicitaría un nuevo valor connotado del lexema, a saber, una especie de entidad divina, coagente con el intermediario humano, del hecho que el verbo refiere. Conforme a la fórmula del valor connotativo del lexema, cabría decir que el E1, la entidad agente del bautismo, se ha como duplicado, de modo que Jesucristo (E1') sería el avalista divino de su vicario en la tierra (cuya referencia se evita por recurso a la pasiva), que es el que de hecho lleva a cabo la acción de bautizar.

La construcción (un hapax en el corpus) también podría explicarse en todo caso como un uso de $\dot{\varepsilon} v$ por $\varepsilon i \zeta^{11}$.

D. Por último encontramos la preposición expresando una relación adyacente o externa, en concreto de lugar: refiere dónde se realiza el bautismo: en el desierto,

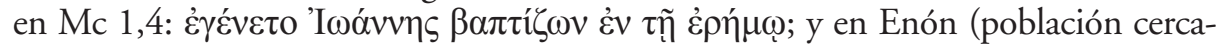
na a Salim, famosa por la abundancia de sus aguas: del contexto se deduce, pues,

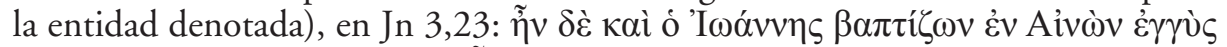

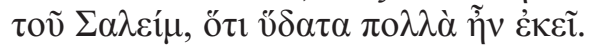

\section{CON LA PREPOSICIÓN vं $\pi$ ò}

Se usa esta preposición para hacer presente, en la frase, el primero de los valores connotados del lexema, la relación de agentividad (R1) con una entidad animada

\footnotetext{
${ }^{11}$ Para el intercambio en el uso de estas preposiciones en el griego helenístico, cf. Zerwick,
} 1997: 57. 
personal (E1). La preposición relaciona con el lexema el agente personal del bautismo, que, en la variante estilística activa, se formula en nominativo como sujeto del verbo. Esta entidad agente es Juan el Bautista (ya mencionado explícitamente, ya referido

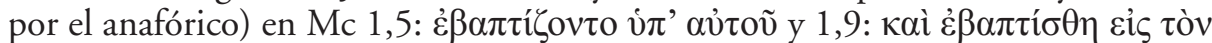

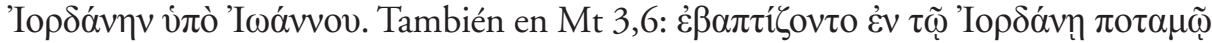

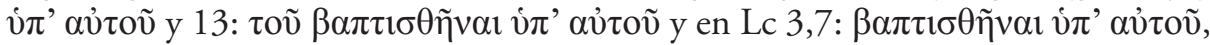

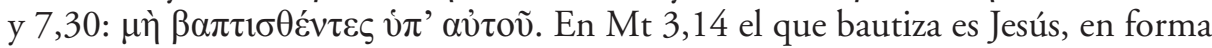

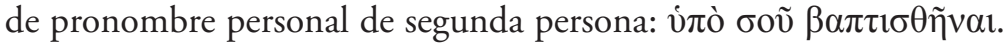

\section{CON LA PREPOSICIÓN EIS}

A. El sintagma preposicional expresa una relación de finalidad entre dos hechos, a saber, el bautismo y un nuevo estado de la entidad que lo recibe. Así lo encontramos

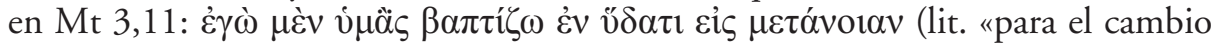
de mente»); $y$, aunque en dependencia de la forma sustantiva del lexema, también

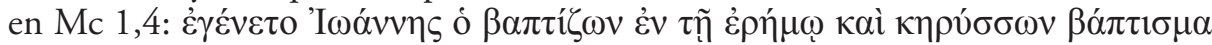

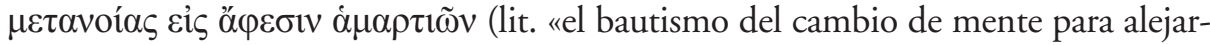

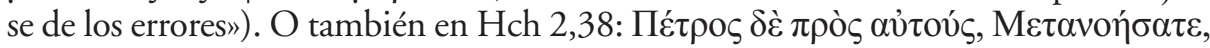

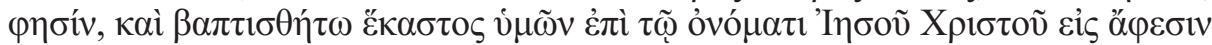

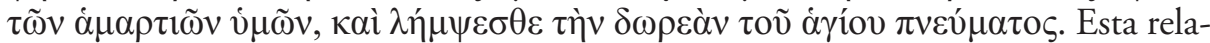
ción sintáctica resulta una prueba contundente del sentido metafórico del lexema verbal en el NT: $\beta \alpha \pi \tau i \zeta \omega$ es, en este corpus, sin duda, un hecho que confiere al bautizado un cambio de cualidad, una limpieza no meramente física, sino también psíquica, espiritual, ritual. El sintagma preposicional explicita pues el valor simbólico del bautismo, en cuanto que rito con una finalidad determinada.

B. También se usa esta preposición para expresar una relación externa de pertenencia a un grupo, que es, por así decir, el garante de que se ha llevado a cabo la limpieza espiritual que el bautizarse supone. Lo cual implica, claro, que el término se usa en sentido simbólico-religioso, que denota un rito específico que vincula al bautizado con un grupo de correlegionarios, un rito, en definitiva, de iniciación. Así

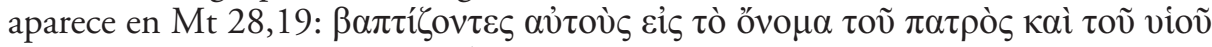

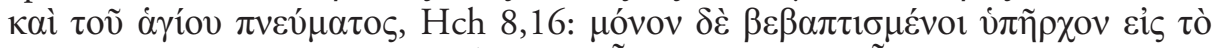

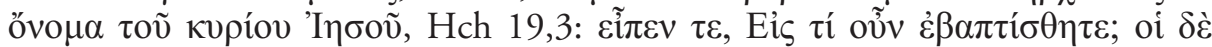

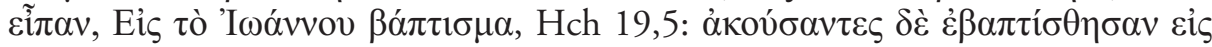

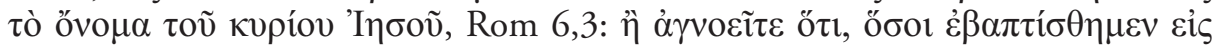

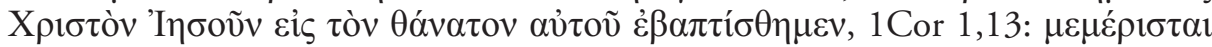

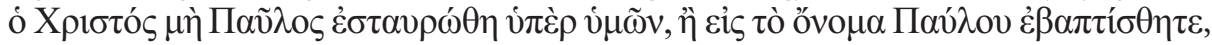

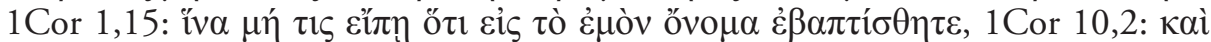

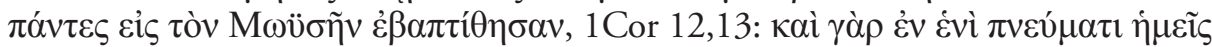

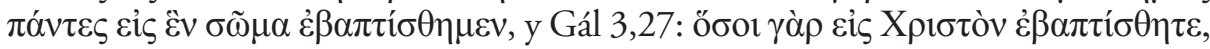
X del señor Jesús, el bautismo de Juan, Cristo Jesús, su muerte, el nombre de Pablo (en dos ocasiones, una de ellas referido mediante el posesivo de primera persona), Moisés, un solo cuerpo y Cristo resultan ser las especies semánticas regidas por 
la preposición, o sea, las entidades garantes de que el bautismo liga al bautizado al grupo, lo hace cristiano.

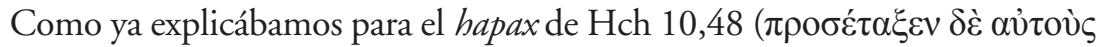

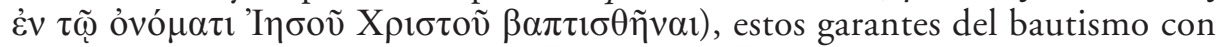
los que la preposición relaciona el lexema verbal se nos presentan como una especie de duplicado del E1, de la entidad agente del mismo, lo cual vendría a confirmarse por el hecho de que, en casi todos estos casos, el verbo se formula en pasiva y no se explicita, en ningún caso, el E1 de la fórmula de Mateos mediante la construcción con virò.

Respecto a las diversas entidades «especulares», regidas por la preposición, que validan el bautismo, bien merecería cada una un comentario que nos llevaría a un ámbito de reflexión teológica que excede del objetivo de este modesto estudio. Baste señalar la nítida diferencia entre las entidades referidas por los cuatro evangelios y los Hechos, por un lado, y las mencionadas por Pablo de Tarso, por otro.

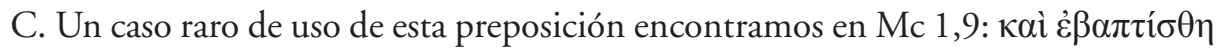

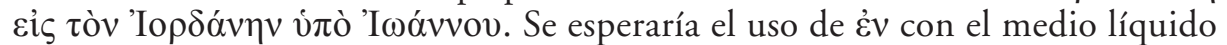
al que se alude (el río Jordán), y encontramos sin embargo eiç. Puede explicarse por un suplantamiento de las funciones de $\dot{\varepsilon} v$ por parte de $\varepsilon i \zeta \zeta$. Sin embargo, es también plausible que se emplee esta preposición para explicitar plásticamente la direccionalidad del movimiento. El uso de cǐc dibujaría la imagen de Jesús entrando en el río Jordán para ser bautizado por su primo, conforme al rito primigenio. Sea como fuere, la preposición relacionaría aquí la acción del verbo con la entidad denotada, el medio líquido en que se sumerge el bautizado.

\section{CON LA PREPOSICIÓN vi $\pi \grave{\varepsilon} \rho$}

Encontramos en el corpus sólo dos casos de uso de esta preposición con este lexema verbal, explicitando en ambos una relación extrínseca con una entidad personal, aunque la entidad relacionada viene a ocupar el sitio de la E2 connotada, o sea, el beneficiario de la acción del bautismo, y convierte al E2, objeto real de la acción, en mero intermediario. La construcción presupone, evidentemente (la purificación es el beneficio), que el verbo se usa en sentido simbólico-religioso.

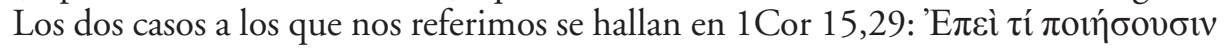

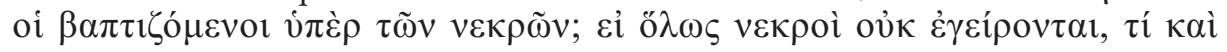

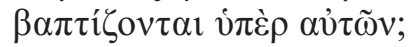

De la misma forma que hemos encontrado en varios pasajes (en el hapax de Hch, 10,48 con la preposición غ̇v y en el de Hch, 2,38 con غ̇ंì, así como en otros con $\varepsilon i \zeta$ que pueden entenderse en sentido semejante) a Jesucristo como coautor del bautismo que, de hecho, lleva a cabo otro en su nombre, ahora son los muertos los beneficiarios de un bautismo que, de hecho, reciben otros en su lugar.

\section{CON LA PREPOSICIÓN Ė $\pi \grave{~}$}

Sólo se documenta un caso de uso de esta preposición con el lexema consi-

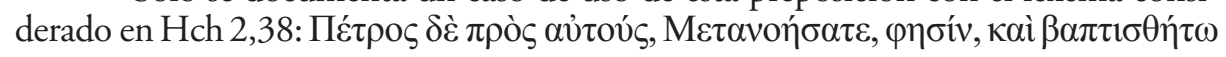




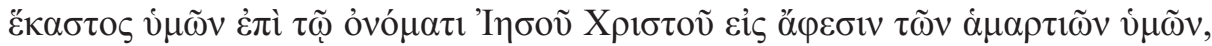

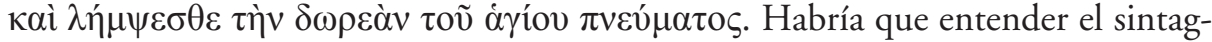
ma en este contexto como «en el nombre de Jesucristo», y en tal caso serviría la construcción preposicional para hacer explícita una connotación (no contemplada en la definición semántica de la que partíamos) del verbo regente, a saber, la relación con una entidad coautora o garante de la acción que el verbo refiere. Este análisis encontraría una prueba de apoyo en el hecho de que, en algunos manuscritos, figure el índice preposicional \&̇v, lo que haría idéntica la construcción a la de Hch 10,48, que habíamos considerado un hapax.

Sirva la tabla que sigue de inventario y clasificación de los usos analizados del verbo $\beta \alpha \pi \tau i \zeta \omega$ con sintagmas preposicionales.

\begin{tabular}{|c|c|c|c|}
\hline & Denotación & Connotación & Circunstancia \\
\hline \multirow[t]{3}{*}{$\dot{\varepsilon} V$} & 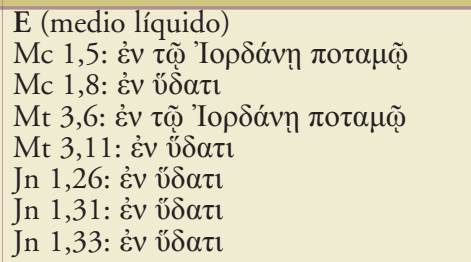 & & 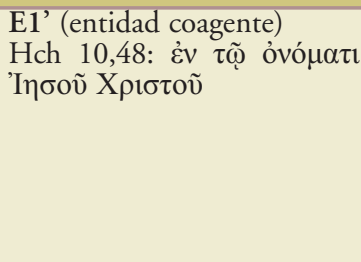 \\
\hline & 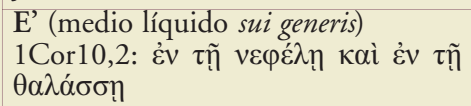 & & \\
\hline & 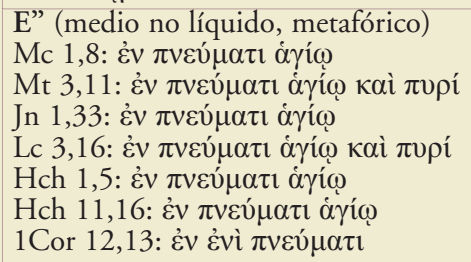 & & 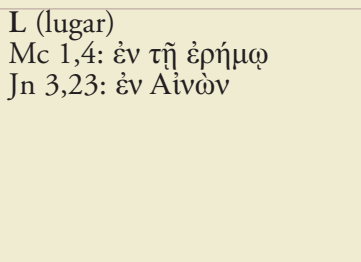 \\
\hline نंđò & & 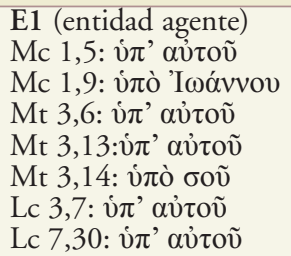 & \\
\hline Eis & 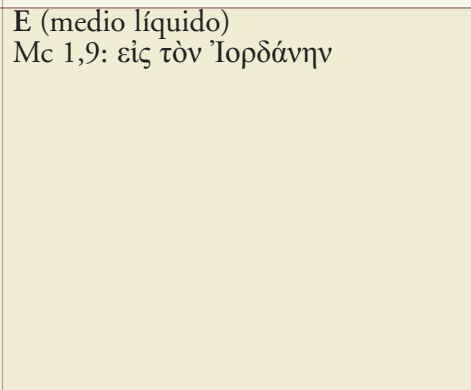 & 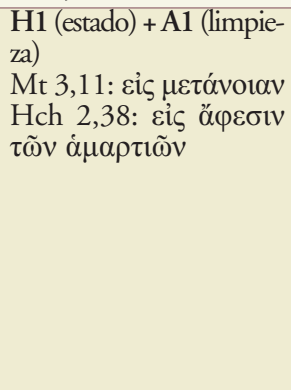 & 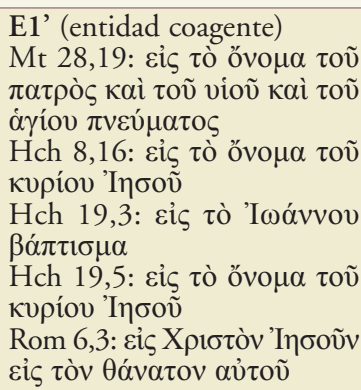 \\
\hline
\end{tabular}




\begin{tabular}{|c|c|}
\hline Eis & 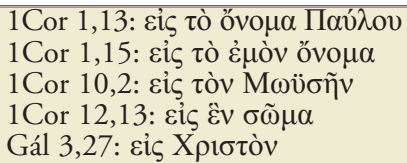 \\
\hline$\dot{v} \pi \dot{\varepsilon} \rho$ & 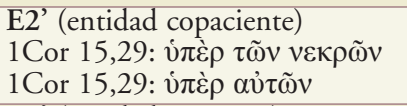 \\
\hline$\dot{\varepsilon} \pi i$ & 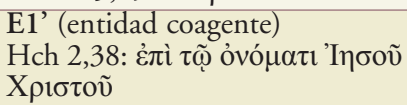 \\
\hline
\end{tabular}

[Tabla de elaboración propia]

\section{CONCLUSIONES}

En qué sentido puedan contribuir estas investigaciones gramaticales, digamos que sintáctico-semánticas, a la exégesis de los textos es lo que pretendemos mostrar con las siguientes inferencias y conclusiones:

1. El significado del verbo sufre, evidentemente, un paulatino proceso de abstracción. En Mateo, Marcos y Juan, hay pruebas sintácticas de que el bautismo implica una inmersión en un medio líquido. Los posibles dativos instrumentales de Lucas y Hechos acaso nos indiquen que el agua entonces no era ya un recipiente donde se mete el bautizado sino un acompañante de la ceremonia, un instrumento al servicio del rito.

De hecho el bautismo en espíritu santo y fuego que anuncia Juan el Bautista como propio del que ha de venir tras él implica una abstracción, una intelectualización del ritual, un lavamiento en sentido simbólico, que dista mucho del bautismo que los fariseos reprochaban a los discípulos de Jesús no hacer antes de la comida.

Con este significado primordial, no metaforizado, encontramos al verbo usado sólo en dos ocasiones en el corpus al que nos atenemos:

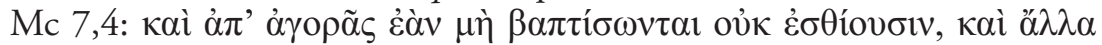

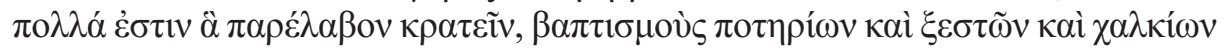

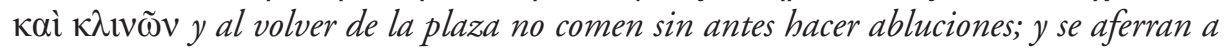
otras muchas cosas que han recibido por tradición, como enjuagar vasos, jarras y ollas.

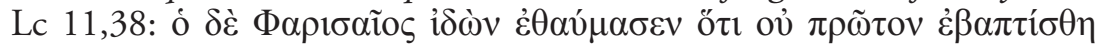

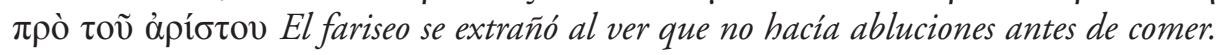

2. El hecho de que en Marcos, Mateo y Juan se use la preposición घ̇v fundamentalmente para explicitar la relación con la entidad denotada y zis para explicitar la relación entre el bautizarse y la purificación consiguiente, contrasta con el uso de estas preposiciones en Lucas, Hechos y Pablo, donde se emplean más frecuentemente para indicar el grupo al que se adscribe el bautizado. Ya se sabe mejor qué es bautizarse. No hay que explicar qué es, ni siquiera para qué sirve, sino más bien en qué nos convierte, a qué grupo nos hace pertenecer. 
Así, el bautizar de los fariseos sería, a ojos de los cristianos, una tradición, más bien utilitaria, pero vacía ya de sentido religioso.

Juan el Bautista bautiza de manera tradicional, aunque confiere un cierto valor simbólico al bautismo.

Cristo bautiza para una limpieza metafórica, simbólica, psíquica, espiritual. Pablo bautiza para engrosar las filas de sus discípulos.

3. Hemos visto pues cómo el significado esencial de la palabra (lo que el profesor Mateos llamó denotación) se mantiene (salvo en casos de metaforización extrema), a pesar de la relación sintáctica con cualquier otra palabra, pero que sus valores connotados se ponen de manifiesto o no, según los complementos sintácticos con los que se construya. Y ello matiza sin duda el significado de la palabra $y$, con él, el sentido de las frases en las que se emplea.

4. Podría inferirse de nuestra investigación que lo semántico y lo sintáctico están en relación estrecha, en el sentido de que los valores semánticos de las palabras no son absolutos ni inmutables, sino que se van forjando con el uso de las mismas en contextos sintácticos diversos.

RECIBIDO: julio 2019; ACEPTADO: octubre 2019.

\section{REFERENCIAS BIBLIOGRÁFICAS}

BaUeR, W. (1971): Wörterbuch zum Neuen Testament, de Gruyter, Berlín-Nueva York.

BW = BibleWorks 10 (2015), BibleWorks LLC [BibleWorks 7 (2003). Software for Biblical Exegesis and Research, BibleWorks, Virginia].

Delgado JARA, I. (2004): «Estudio de los valores de las preposiciones 'propias' en el griego del Nuevo Testamento», Helmántica 55: 149-188.

Díaz Tejera, A. (1971): «Puntos de contacto entre Sintaxis y Semántica», RSEL 1: 361-370.

GnilKa, J. (1998): Pablo de Tarso, apóstol y testigo, Herder, Barcelona.

Mateos, J. (1989): Método de análisis semántico aplicado al griego del Nuevo Testamento, Estudios de Filología Neotestamentaria, Ediciones El Almendro, Córdoba.

Mateos, J. - SchÖKEl, L. A. (19872/20104): Nuevo Testamento, Ediciones Cristiandad, Madrid.

Mateos, J. (†) - Peláez, J. - Grupo de Análisis Semántico de Córdoba (GASCO) (2012): Diccionario

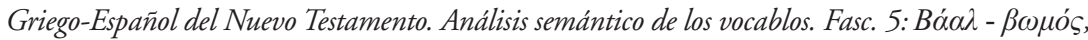
Ediciones El Almendro - Fundación Épsilon, Córdoba.

Merino SÁnchez, M. (2017): «La preposición ảđó en el griego del Nuevo Testamento. Algunos casos de controversia», Cuadernos de filología clásica: Estudios griegos e indoeuropeos 27: 31-47.

Merino SÁnCHEZ, M. (2019): «La preposición cỉ̧ en el griego del Nuevo Testamento. Ensayo de análisis semántico", Humanitas: 73: 23-51.

NA28 = Nestle, E.-Aland, K. (eds.) (2012): Novum Testamentum Graece, Deutsche Bibelgesellschaft, Stuttgart $\left[28^{\text {th }}\right.$ revised edition]. 
Peláez del Rosal, J. (1996): Metodología del Diccionario Griego-Español del Nuevo Testamento, Ediciones El Almendro, Córdoba.

Peláez del Rosal, J. (2003): «La metodología del Diccionario Griego-Español del Nuevo Testamento», en S. Torallas Tovar (ed.), Memoria de los Seminarios de Filología e Historia, C.S.I.C., Madrid, pp. 79-94.

PELÁEZ DEL Rosal, J. (2012): «Factor contextual y cambio de significado. De las palabras en el Diccionario Griego-Español del Nuevo Testamento (DGENT)», en A. Nomdedeu Rull et al. (coords.), Avances en lexicografia hispánica, t. 1, Publications URV, Tarragona, pp. 81-90.

Piñero Sáenz, A. (ed.) (1995): Orígenes del cristianismo. Antecedentes y primeros pasos, Ediciones El Almendro, Madrid.

Piñero, A. - PelÁez, J. (1995): El Nuevo Testamento. Introducción a los primeros escritos escritos cristianos, Ediciones El Almendro, Córdoba.

Rigaux, B. (1956): Saint Paul: les epîtres aux Thessaloniciens, Ed. Duculot-Gabalda, París.

ZERWICK, M. (1997): El griego del Nuevo Testamento, Verbo Divino, Estella (Navarra).

ZerWICK, M. (2008): Análisis Gramatical del Griego del Nuevo Testamento, Verbo Divino, Madrid. 